\title{
Artículos
}

\section{Consideraciones sobre la edición electrónica de revistas en internet}

\author{
Por Elena Fernández Sánchez e Isabel Fernández Morales
}

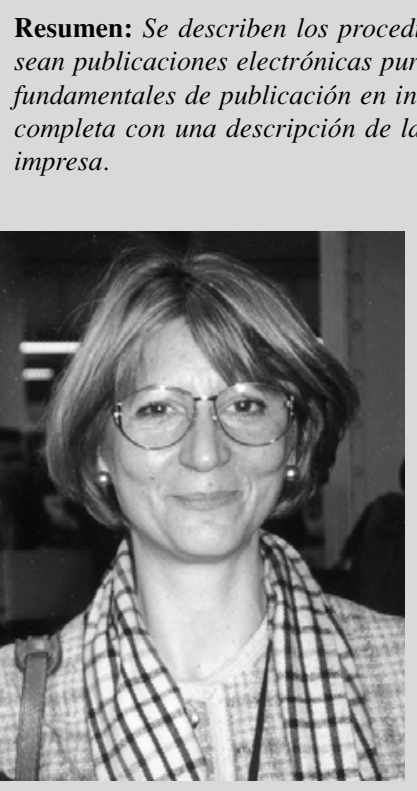

Elena Fernández Sánchez
Palabras clave: Revistas electrónicas, Internet, Digitalización, Conversión de formatos, Página web, Portable document format ( $p d f$ ).

\section{Title: Web journal publishing: a general perspective}

Abstract: Description of the basic procedures for publishing electronic journals, including both titles that exist only in an electronic version and those that are electronic versions of a printed journal. The authors describe the basic formats used for publishing on the internet as well as the tools and procedures necessary for creating web pages and documents in $p d f$. The advantages of e-publishing as compared to the printing process are also explored.

Keywords: Electronic journals, Internet, Digitization, Format conversion, Web page, Portable document format $(p d f)$.

Fernández Sánchez, Elena; Fernández Morales, Isabel. "Consideraciones sobre la edición electrónica de revistas en internet”. En: El profesional de la información, 2000, marzo, v. 9, n. 3, pp. 4-12
La principal novedad en internet durante el último año ha sido la proliferación de los portales de acceso a la información, algunos de los cuales reciben la visita mensual de más de treinta millones de usuarios que buscan información a su medida. Se diferencian entre sí sólo por el diseño y la imagen, ya que los contenidos son prácticamente los mismos: noticias en tiempo real, buscadores, comercio electrónico, canales temáticos e información especializada. Precisamente la última cuestión es la que está desencadenando el aumento (o más bien la conversión) de los grandes portales en comunidades virtuales especializadas. Esta será, según los expertos de la Red, la tendencia que se desarrollará en los próximos años.

En las grandes comunidades virtuales ya existentes, uno de los servicios mas demandados es, además de las noticias en tiempo real, aquel que ofrecen a sus residentes para el acceso a artículos en texto completo, bien buscándolos el propio usuario o por canales "push" a través de los cuales se reciben, por correo electrónico y de forma periódica, trabajos especializados de acuerdo con sus necesidades de información.
En cuanto a la implantación en internet de las revistas electrónicas los datos son los siguientes: 5 años atrás su número era de 140 y hace únicamente 24 meses la mayoría de estas publicaciones no ofrecía más que el sumario de su edición en papel. Desde entonces, las editoriales tradicionales han invadido la Red con versiones completas de sus revistas y la cifra supera ya las 7.000. La editora holandesa Elsevier tiene más de 1.200, la alemana Springer Verlag 360 y la inglesa Academic Press 174. Respecto a la prensa diaria, hoy día no hay prácticamente ningún periódico de gran tirada que no tenga su correspondiente traslación digital.

Es interesante meditar un poco sobre la revolución que se ha originado en el mundo editorial. Los papeles de autor, editor y distribuidor de las revistas científicas han cambiado radicalmente con la edición electrónica, ya que el primero puede asumir las labores de edición y de distribución de sus propios artículos. El máximo exponente de este cambio es el hecho de que en determinadas áreas del conocimiento, como es el caso de la física, sean los propios investigadores quienes pongan en la Red sus trabajos (preprints) antes de publicarlos 
en las revistas especializadas: un ejemplo es Los Álamos National Laboratory y el European Laboratory for Particle Physics.

http://www.lanl.gov

http://preprints.cern.ch

En el ámbito académico, que demanda las últimas novedades e innovaciones, esto supone un enorme logro. La información está accesible en un tiempo mínimo (los artículos se encuentran disponibles en cuanto son producidos por el autor) y además se favorece la comunicación entre la comunidad científica y la generación de ideas.

Generalmente los que publican sus trabajos suelen ser investigadores familiarizados con esta tecnología, sobre todo en el manejo de las herramientas que hacen posible la edición electrónica. La gran mayoría de internautas, si bien la utiliza para obtener información, no la usa como medio para difundir sus investigaciones. Precisamente el objetivo de este trabajo es exponer un método estructurado y simple referente a la edición electrónica destinado a todos aquellos que quieran emprender la aventura de la publicación de documentos digitalmente.

\section{Situación actual de la edición electrónica en España}

Los editores científicos españoles fueron de los primeros que se subieron al tren de internet alrededor de 1995. Es cierto que sólo presentaban el índice de contenidos y poco más, pero es necesario reconocer que se instalaron antes que muchos otros internacionales de revistas de mayor prestigio, anticipándose incluso a su propio público lector. Desde entonces su número ha experimentado un enorme crecimiento y han surgido publicaciones electrónicas puras, aunque el interés de los científicos y usuarios especializados sigue siendo el mismo: la calidad en los contenidos y su nivel de difusión.

Muchas de las revistas recogidas en el Índice español de ciencia y tecnología editado por el Cindoc están en este formato, aunque son muy escasas las que permiten obtener el texto completo de sus artículos. A nivel internacional lo que está primando por parte de las grandes firmas de bases de datos es la posibilidad de ofrecerlo a través de enlaces a los servidores de las revistas. Esta tendencia estaba muy explícita en la última edición de la feria más relevante del mundo de la información: el International online information meeting, celebrado en Londres durante el mes de diciembre de 1999.

\section{Clasificación de las revistas digitales}

Existen dos tipos principalmente: las publicaciones que son la versión digital de la impresa y las electrónicas puras. Para las revistas científicas o de divulgación es fácil distinguir una categoría de otra. Las primeras presentan un formato y diseño análogos a los de su edición en papel, destacando fundamentalmente todo lo que tiene que ver con la parte gráfica: las imágenes son escasas, no suelen poseer la opción de poder aumentarlas en el caso de que el usuario lo necesite y su organización visual sigue las normas del papel.

\section{«Las editoriales tradicionales han invadido la Red con versio- nes completas de sus revistas y la cifra supera ya las 7.000 »}

Las publicaciones digitales puras han nacido para la Red y por tanto exhiben otra estructura que es fácil de detectar. En general muestran un espacio visual mucho más rico y colorista, los sumarios tienen formas más elaboradas (no sólo un índice con el nombre del trabajo y el título del autor), ofrecen información detallada sobre el autor, se presenta un sumario del artículo con sólo seleccionarlo mediante aplicaciones, se puede acceder a todos los contenidos a través de búsquedas en bases de datos, y el sistema de enlaces a otras fuentes de información es muy amplio (recursos web, referencias bibliográficas de otros textos, bases de datos, etc.).

En el caso de los diarios se observa que las versiones digitales son meras copias de las realizadas en papel. Por ejemplo, no se explota el concepto de hipertextualidad de una noticia a otra, ni tampoco existe una organización visual adaptada al formato de pantalla.

\section{Mejoras presentes en las revistas electrónicas respecto a la edición impresa}

- Disminución del plazo de espera para su publicación: se ha reducido la media (que en el caso del papel es de 6-8 meses) a una semana e incluso, en determinadas situaciones, se presentan los trabajos antes de que estén totalmente terminados: working papers.

- Universalidad de la información: por medio de su difusión en internet están presentes en cualquier lugar del mundo sin los enormes gastos que supondría otro canal.

- Reducción de los costes de edición hasta en un $40-50 \%$.

- Posibilidad de añadir nuevos soportes a los documentos: vídeo, audio, realidad virtual, etc. 
— Capacidad de establecer una comunicación bidireccional con el destinatario de la información, que permite conocer sus impresiones en tiempo real haciendo llegar sus consultas, peticiones, sugerencias, etc.

- El sistema de citas es mucho más rico que en el formato impreso: se puede enlazar con diferentes recursos de información.

— La obtención del artículo a texto completo es inmediata y fácil, ya que lo habitual es que se encuentren almacenados en bases de datos y su acceso se realiza por los procedimientos habituales de los sistemas de recuperación documentales.

\section{Procedimientos y herramientas básicas para la edición de documentos en internet}

\section{Características de los documentos electrónicos.}

- Combinan diferentes unidades de información (texto, imágenes fijas o en movimiento, voz, gráficos, etc.).

- Su contenido puede cambiar de soporte con el tiempo.

— Permite establecer relaciones con otros documentos.

— La estructura física carece de importancia.

— Su contenido puede ser modificado rápidamente.

— Facilidad en el proceso de generar copias.

- Admite múltiples formatos de lectura, variaciones estructurales y estéticas, etc.

Es por lo que actualmente se habla de documentos inteligentes como depósitos dinámicos de conjuntos de información creados por distintas aplicaciones y que son revisados y actualizados de manera automática.

\section{Formatos para publicar en el web.}

Si bien es cierto que el protocolo http soporta cualquier tipo de archivo, hoy por hoy el estándar adopta-

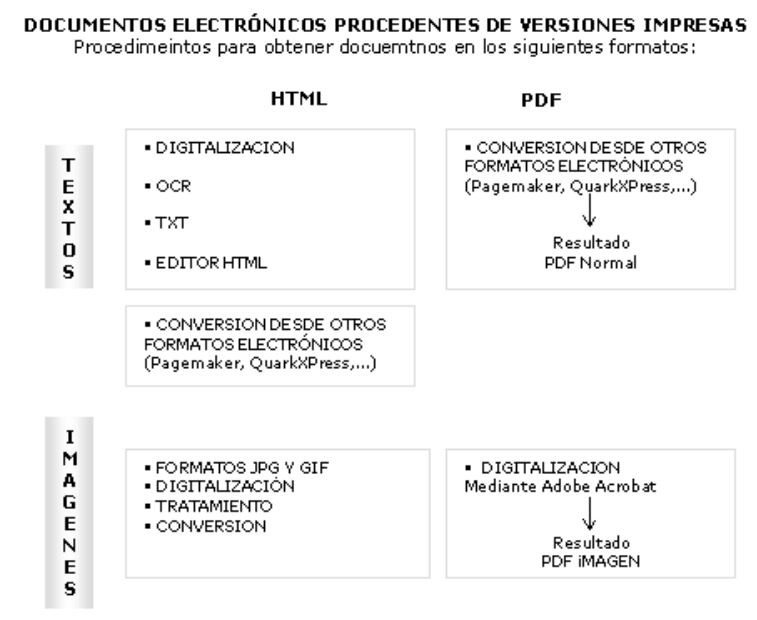

do para poner la información a través del web es html. La posibilidad de poder trabajar otros lenguajes reside en las aplicaciones de visualización que soporten los navegadores que, ciertamente, están aumentando. La mayor parte de lo que se publica en internet está en formato html (es decir, archivos con extensión html o $\mathrm{htm}$ ), que es compatible con todos los navegadores (Internet Explorer y Netscape Navigator, principalmente). Otro de los formatos más difundidos por la Red es pdf (portable document format), visualizado por Acrobat Reader, cuya difusión es gratuita. Cuando se quiere ver un documento de este tipo, el navegador llama automáticamente al programa que tiene asociado si previamente se ha instalado en el ordenador. Se suele ofrecer la posibilidad de obtenerlo desde la página web que da acceso a los archivos pdf.

\section{«Los papeles de autor, editor y distribuidor de las revistas científicas han cambiado radi- calmente con la edición elec- trónica»}

Actualmente se está desarrollando un nuevo lenguaje de etiquetado: xml (extensible markup language). Es importante destacar que no es una ampliación de html, sino que se puede definir como un lenguaje que no posee etiquetas prefijadas con anterioridad, ya que es el propio diseñador quien las crea a su conveniencia dependiendo del contenido del documento. También hay que aclarar que es más un sistema de tratamiento de la información que un simple lenguaje de descripción. Actualmente se puede utilizar xml en el web pero, dado que tiene una normativa nueva, no todas las herramientas relacionadas con internet son capaces de trabajar con él. En cuanto a los navegadores, Explorer 5.0 sí lo soporta mientras que Netscape 4.x no lo hace, aunque se espera que en la 5.0 sí lo permita. La versión 1.0 de xml es ya definitiva. Sin embargo las demás normativas que le acompañan van pasando del estado de borrador de trabajo a recomendación.

http://www.w3c.org

Por tanto, en adelante sólo nos referiremos a los documentos en html y pdf, y se describirá un método para obtenerlos, diferenciando si se trata de digitales puros o si proceden de versiones impresas.

a. Documentos html. Las páginas web están construidas fundamentalmente con códigos html, un lenguaje que no es propiamente de programación pero que acepta que se le introduzcan otros que sí lo son como JavaScript. Deriva del sgml (standard generalized markup language) agrupando una serie de comandos o etiquetas que son interpretados por el navegador y se 
ha constituido como una excelente forma de desarrollar documentos informativos independientes de la plataforma. Es muy sencillo crear una página que combine texto y gráficos en un único documento con este lenguaje. La inclusión de mapas de imágenes activas o gifs animados, junto con la inserción de formularios le han proporcionado cierta interactividad. Sin embargo, el diseño ha estado limitado en cuanto al formato de los textos, el control de la maquetación y la capacidad de alterar su contenido.

Dados estos límites del html básico (3.2), el último avance que ha tenido lugar ha sido la creación de la versión 4.0, llamada html dinámico, que es una colección de tecnologías nuevas, y ya existentes, que se han diseñado para optimizar y flexibilizar estas aplicaciones basadas en la Red. Reúne un cierto número de tecnologías de red que funcionan en el entorno de una estructura fácil de gestionar y aprovecha otras como las hojas de estilo en cascada, ActiveX, JavaScript y VBScript.

Html dinámico intenta aportar un nuevo grado de flexibilidad y de desarrollo. El diseñador tiene ahora la capacidad de controlar su maquetación y su estilo (tipo y formato de letra, posicionamiento, etc.), y la incorporación y generación automática de datos en la página (producción dinámica de tablas).

b. Documentos pdf. Se crean con el programa Adobe Acrobat conservando fielmente el contenido y la apariencia de los originales (incluidos gráficos y fuentes) pudiendo distribuirse por correo electrónico o almacenarse en el web. Representa el texto y los gráficos utilizando un modelo de imágenes similar al PostScript. Al igual que PostScript, una descripción de página pdf dibuja una página asignando "manchas" en áreas seleccionadas: textos, gráficos, fotografias, etc. . Estos archivos son portables (se pueden intercambiar entre diversos entornos de hardware y sistemas operativos).

Se pueden crear convirtiendo archivos de cualquier otro formato o digitalizando otros impresos. Una vez hecho esto se pueden añadir elementos multimedia, enlaces, botones e índices buscables.

- Conversión de archivos electrónicos a formato pdf: Acrobat permite hacerla con un archivo electrónico de prácticamente cualquier aplicación. Puede usar dos utilidades diferentes: PdfWriter o Acrobat Distiller. En general el primero la realiza más deprisa, mientras que el segundo proporciona un mayor control sobre el proceso, así como una calidad superior. El resultado es un archivo pdf normal en el que es posible hacer búsquedas textuales.

- Conversión de documentos digitalizados a pdf. Se puede utilizar Acrobat con un escáner para crearlo a partir de un documento en papel. El archivo resul-
CREACION DE DOCUMENTOS PDF

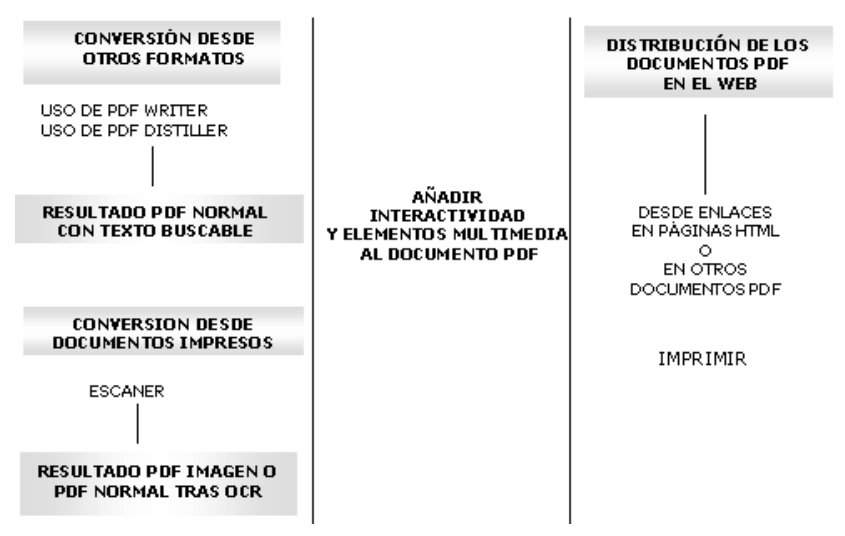

tante es de sólo imagen, es decir, un mapa de bits de las páginas para visualizar en Acrobat pero en el que no se permiten realizar búsquedas.

\section{Método para la elaboración de documentos digitales puros.}

Como ya se ha mencionado en un apartado anterior son aquellos que nacen para la Red. Por tanto, no tienen necesidad de ninguna conversión a partir de otro impreso, ya que el documento se va a crear directamente. A continuación se expone el procedimiento para la edición tanto de la parte textual como de la gráfica.

a. Generación de textos: se pueden crear en html o pdf. Las herramientas para elaborar los primeros pueden ser:

- Editores de texto que permiten conversión directa a html: Microsoft Word y todas las aplicaciones de Microsoft Office.

- Un procesador de texto. Es válido cualquiera, siempre que no lo formatee. Por ello, los más adecuados son los más sencillos (como por ejemplo: Notepad en Windows o SimpleText en Macintosh). En este caso se irá escribiendo el código html manualmente. Luego será interpretado por el navegador. Se deben guardar los ficheros como "sólo texto" añadiendo de forma manual la extensión html o htm.

- Editores de html. Existen ciertos programas que ayudan a automatizar este proceso, pero es muy conveniente comenzar a hacerlo de forma manual para comprender bien la estructura del lenguaje. La mayoría son del tipo wysiwyg (what you see is what you get, "usted ve lo que va a obtener"), es decir, permiten una edición gráfica, igual que podría hacerlo un editor de textos como Word. Algunos de los más completos y versátiles del mercado son Dreamweaver de Macromedia, Pagemill de Adobe, y Hotmetal o FrontPage de Microsoft. Además, Netscape Navigator e Internet Explorer los incluyen como añadidos: Composer $y$ FrontPage Express respectivamente. 
— Es imprescindible un navegador para visualizar la página web y las modificaciones que se vayan realizando, y es recomendable contar con cualquiera de los dos comentados anteriormente en sus últimas actualizaciones ya que no las presentan del mismo modo.

- Conversión de pdf a html. Con la última versión de Adobe Acrobat (la 4.0) es posible hacerlo.

Para crear un documento pdf se puede convertir cualquier archivo procedente de otra aplicación o hacerlo con un documento impreso digitalizado. Para el desarrollo de uno digital puro se emplea la primera opción. Es decir, se crea uno de texto (con Word, por ejemplo) y después se transforma a pdf con PdfWriter o Distiller.

\section{«Los editores científicos espa- ñoles fueron de los primeros que se subieron al tren de inter- net alrededor del año 1995»}

b. Gestión de imágenes: el tratamiento de este material —que se refiere a fotografías, iconos o cualquier tipo de gráfico - requiere dos etapas: la obtención de los archivos que se deseen insertar y su tratamiento. La primera se puede realizar de tres maneras básicas:

1. Capturar las imágenes mediante escáner o cámara digital. Los escaners llevan asociados su propio software de digitalización, y cada modelo ofrece prestaciones diferentes en cuanto a resolución, profundidad, velocidad, área de digitalización. Pueden incluir módulos para $O C R$ (reconocimiento óptico de caracteres) o tratamiento y organización de las imágenes.

2. Creación y/o edición mediante programas de dibujo y tratamiento gráfico. Entre los programas más difundidos para realizar diseños propios se pueden citar: Adobe Illustrator, Corel Draw, Fireworks y Freehand de Macromedia, y para el retoque de imágenes Photoshop.

3. Conversión de gráficos: por ejemplo de Excel a gif automáticamente desde la propia hoja de cálculo.

Los archivos de imagen que pueden insertarse en el formato html deben tener la extensión jpg (para imágenes de alta calidad como fotografías) o gif (para otras de más baja como iconos, barras, puntos, etc.). Se ha de procurar disminuir al máximo el tamaño para acelerar la navegación y descarga por parte de los usuarios de internet. Algunos consejos para ello serían:

- Recortar pixeles innecesarios con un programa de retoque gráfico.

— Reducir el número de colores a utilizar.
- Usar niveles de compresión altos, evaluando la calidad resultante.

— Digitalizar a 72 píxeles por pulgada, que es el máximo que es capaz de mostrar la mayoría de los monitores.

- El fichero de una imagen no debe sobrepasar los $100 \mathrm{~Kb}$ y sería mejor si fuera aún más pequeño. Tampoco conviene que la extensión en pantalla sea mayor de 500 x 400 píxeles para no obligar al usuario a tener que desplazarla con los cursores para visualizarla entera.

- Utilizar thumbnails (reproducciones en pequeño que enlazan con la imagen grande). De esta manera es el internauta quien puede elegir cuáles cargar.

El método de compresión utilizado por el formato gif es muy conveniente para áreas monocolor como las que puede haber, por ejemplo, en un diagrama sencillo. Para el caso de imágenes más complicadas (fotografías) es mejor trabajar con jpg, que ofrece una calidad mayor y un tamaño de fichero menor y, entre los diferentes niveles de compresión que permite conviene escoger uno intermedio. Es posible convertirlas a este formato desde la mayoría de programas de retoque fotográfico, siendo Photoshop el más popular y uno de los más completos.

c. Utilización de hiperenlaces. Ya se ha comentado anteriormente que una de las ventajas que presenta la edición electrónica frente a la convencional impresa, es la utilización de vínculos a recursos de información muy variados: servidores, bases de datos, referencias de otros documentos, noticias de prensa, etc. Esto enriquece enormemente el valor del documento y reduce considerablemente el tiempo en la obtención de la información procedente de estas fuentes. Pero además de estos enlaces externos se pueden realizar otros internos de navegación al propio documento, lo que también supone un ahorro de tiempo al lector ya que a veces su interés está centrado sólo en una o varias partes del mismo.

\section{Método para la elaboración de documentos electrónicos que proceden de la digitalización de otros existentes previamente en edición impresa.}

Es el caso de las revistas impresas o noticias de prensa que posteriormente se han convertido a formato electrónico pero respetando de forma exacta tanto el contenido como el diseño del documento primitivo original. Para gestionar la información textual de estas publicaciones se puede optar por una de la siguientes posibilidades:

a. Capturar sus textos mediante la digitalización de los originales impresos a través de programas de $O C R$ 
(optical character recognition). Así se obtiene un documento en texto que puede convertirse a html o a pdf normal. Para conseguir el texto de un documento digitalizado es necesario utilizar dicho software de reconocimiento óptico de caracteres, pues convierte una imagen en texto editable por el ordenador. Durante el $O C R$ el programa analiza una imagen y define caracteres de texto. Una vez terminado se podrá exportar éste a diversos programas de procesamiento de texto $\mathrm{y} / \mathrm{u}$ hoja de cálculo. Normalmente sólo reconocen correctamente caracteres impresos a máquina (mecanografiado por ejemplo) o con letra de imprenta.

Las etapas en la ejecución de un $O C R$ son:

- explorar con el escáner un documento o cargar un archivo de imagen,

- crear zonas para identificar las áreas que se desea reconocer como texto o mantener como gráficos,

- realizar el $O C R$ para convertir la información de texto en caracteres editables,

- exportar el documento al lugar deseado y guardarlo como un tipo de archivo específico (doc, txt, etc.) o copiarlo, llevarlo al Portapapeles y,

- a continuación puede editarse como html o transformarlo como pdf texto.

En cuanto a las imágenes del documento original, todas han de ir archivadas en jpg o gif. De nuevo, y en el caso de que se desee mejorar su calidad, se puede recurrir a programas como Photoshop, que admite multitud de formatos y conversiones entre ellos y que permitirá adaptarlas a la página web. Los más utilizados son: OmniPage, Adobe Acrobat y el software de $O C R$ incluido en el escáner.

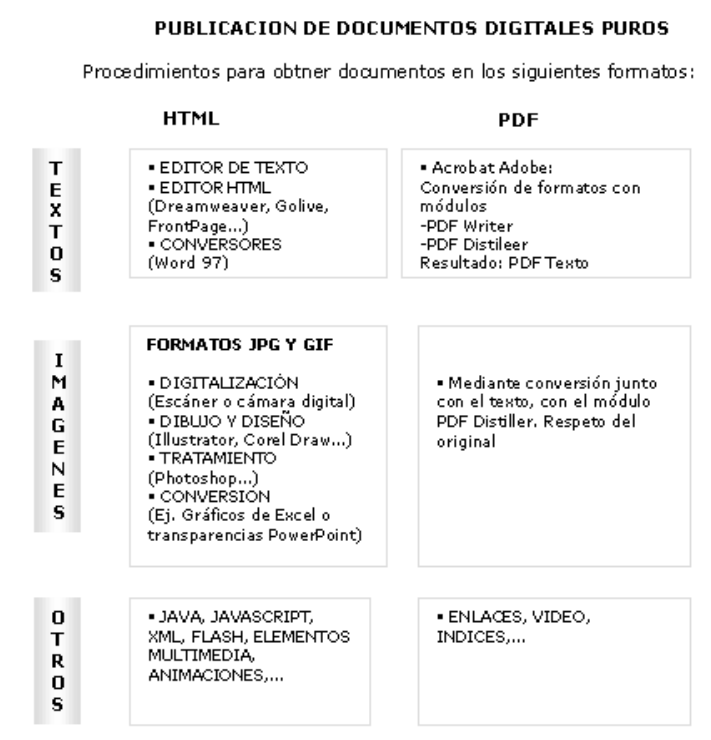

b. Capturar el documento exclusivamente en formato gráfico. Esto supone almacenarlo directamente digitalizado como una imagen, en cuyo caso no se puede recuperar por ninguna palabra del texto. El formato adecuado para ello es pdf, gracias al cual el aspecto será idéntico al original. Ocupará mayor espacio que el pdf de texto y, por supuesto, no permitirá hacer buscable el mismo, aunque todo el proceso es mucho más rápido. Es recomendable efectuar la digitalización en blanco y negro con una resolución de 300 píxeles por pulgada.

\section{«Las publicaciones digitales puras han nacido para la Red y muestran un espacio visual mu- cho más rico y colorista»}

c. Convertir los archivos originales de la publicación a html o pdf. Esta opción supone la conversión de los archivos electrónicos originales de la revista elaborados mediante programas de maquetación como, por ejemplo, PageMaker o QuarkXPress, y que se pueden transformar de forma directa a pdf texto o a html.

\section{Consideraciones sobre el diseño}

Independientemente de la subjetividad inherente a todo proceso de diseño, las publicaciones en internet deberán cumplir los principios básicos característicos de las páginas html. De forma esquemática estos preceptos se enumeran a continuación:

a. Optimización en la recuperación del recurso por parte de los motores de búsqueda. De acuerdo con las normas establecidas es necesario incluir metaetiquetas en la sede web donde se encuentre la publicación para facilitar su acceso a través de los buscadores.

b. Identificación del recurso en todas sus páginas. Es importante para el usuario que cuando se encuentre visualizando un artículo o noticia - que evidentemente está formando parte de un sitio web-identifique el recurso por el nombre o por la organización responsable del mismo. En este sentido, cada página debe contener un logo o algún tipo de información de esta naturaleza, así como enlaces a la anterior, posterior y a la principal.

c. Sencillez y facilidad de acceso a la información respecto a la navegación. Todas las páginas deben contener un enlace a la principal del servidor además de otros que permitan llegar a otras secciones. Es importante facilitar la entrada mediante índices.

d. Legibilidad y color. Es recomendable mostrar especial cuidado a la hora de la asignación de colores, tanto del fondo como de las fuentes, con el fin de ga- 
rantizar la claridad de las páginas y procurar tonalidades atractivas y suficientemente contrastadas.

e. Equilibrio entre la información textual y gráfica. Es necesario alcanzar una armonía razonable entre ambas para conseguir que toda resulte agradable y fácil de leer en general. En este sentido, hay que tener en cuenta dos principios: un exceso de información textual, en cuanto a páginas demasiado largas, resulta tedioso y aburrido para el usuario. Es mejor ofrecer un resumen y permitir que sea él quien, si lo desea, pueda cargar el resto en su ordenador o sencillamente enviarlo a impresión.

El segundo es, justamente, el caso opuesto: demasiada información gráfica disminuye la velocidad en el acceso a las páginas (los archivos de imágenes son grandes) y, a no ser que lleve asociado un enlace a un archivo de texto, el resultado es una información sin contenido, que es justamente lo contrario a uno de los principales objetivos que se pretenden para el futuro: crear una internet con contenidos.

\section{Revistas electrónicas a través de internet que no son aplicaciones web}

Finalmente, es importante mencionar otra forma de editar una publicación digital que cada día está siendo más empleada por grupos que comparten un interés común en determinados temas. Se trata de hacerlo utilizando el sistema de mensajería electrónica. En este caso, el centro emisor y editor recurre a las listas de distribución para enviarla a sus asociados en formato texto o html (actualmente este procedimiento es el más utilizado). Un boletín o revista electrónica que es recibida a través del correo electrónico tiene un carácter mucho más dinámico que la que se encuentra en el web ya que el usuario no tiene que acceder a la información, sino que es ésta la que accede a él. Este sistema conlleva una importante fuente de datos para los editores de la revista, ya que conocen los perfiles de sus asociados.

\section{«Para crear un documento pdf se puede convertir cualquier ar- chivo procedente de otra aplica- ción o hacerlo con un documen- to impreso digitalizado»}

Empieza a haber cada día más boletines que llegan hasta los buzones en formato web, es decir, en html, y que pueden interpretarse por un programa de correo si está configurado para ello. Estas publicaciones resultan atractivas, tienen hiperenlaces, incorporan imágenes y otros elementos multimedia. Sin embargo, también tienen mayor tamaño que una edición en texto simple, con lo que tardan más en transmitirse y ocupan mayor espacio en las cuentas de correo.

La versión en texto simple es mayoritariamente compatible con cualquier lector de correo electrónico, con lo que se asegura que la revista llegará íntegra y sin problemas al suscriptor aunque se pierda vistosidad. Además, una opción que permite la mayoría de ellos es crear dos versiones del mensaje: en html y en texto simple, lo que ocurre por ejemplo con Messenger de Netscape u Outlook Express de Microsoft, aunque puede generar alguna incompatibilidad con programas no adaptados a html. Por eso, a la hora de que el lector se suscriba es oportuno preguntarle en qué formato desea recibirlo para evitar cualquier problema.

\section{Edición de una revista a través de correo} electrónico.

Si va a ser distribuida a texto simple conviene seguir estos pasos:

- Usar un editor para ello, por ejemplo el Bloc de notas o Wordpad. Esto quiere decir que no se podrán usar negritas, subrayados, cursivas ni ningún efecto en el texto.

- Conviene no sobrepasar las 70 caracteres de longitud de las líneas para evitar que se superen los márgenes de un lector de correo.

- Introducir, a modo de barras horizontales separadoras, líneas de guiones para diferenciar secciones y también utilizar sangrías para definir la estructura del documento.

- Una vez escrito el texto, se selecciona, se copia y se pega en el correo electrónico.

- Antes de enviarlo definitivamente a los suscriptores, conviene hacerlo a uno mismo para comprobar cómo lo van a recibir.

Si el formato va a ser html, las fases a realizar son:

- Trabajar con un programa de correo electrónico como los comentados anteriormente que permita editar en este formato.

- Estos editores permiten configurar el texto (tamaño, estilo, color, etc.), insertar tablas, imágenes, líneas horizontales, listas, enlaces, etc.

- Realizar una prueba antes de enviarlo a los abonados.

\section{Gestión de los documentos electrónicos}

Otra de las ventajas importantes que presenta la edición digital respecto a la convencional es, sin duda, la recuperación de los documentos. En el sistema tradicional se realiza a través de bases de datos biblio- 
gráficas que recogen el vaciado de los artículos de las revistas. Una vez localizadas las referencias es necesario obtener los documentos primarios a través de la biblioteca. Esto conlleva un tiempo considerable incluso si es el propio centro quien se encarga de enviarlos por cualquier procedimiento (correo postal, fax, correo electrónico).

Sin embargo, cuando las revistas se encuentran en formato digital la obtención por parte del usuario puede ser instantánea si los artículos se encuentran recogidos en una base de datos. Esto se realiza mediante los módulos clásicos de la gestión documental pero aplicados a este tipo de documentos, por lo que serán factores clave la recuperación de la información mediante la gestión de los atributos de los mismos. En este caso, un ejemplo es MicroIsis en su aplicación para internet, ya que reúne una serie de características que parece fundamental resaltar.

Este programa de la Unesco es de distribución gratuita para organizaciones que se comprometan a no venderlo, no tiene limitación práctica ni por el número de registros (16.000.0000) ni por la extensión, ni por el número de campos (hasta 200, permitiendo incluso aquellos con información gráfica), y el sistema de recuperación documental es bastante completo — admite búsqueda por índices, por varios campos a la vez, con todos los operadores booleanos, truncamiento, etc.- . Posee una gran flexibilidad en el diseño de la pantalla de consulta y presentación de resultados.

\section{Consideraciones sobre los derechos de autor}

Otra de las reflexiones a tener en cuenta es el tema de la defensa de los autores de las publicaciones electrónicas. La protección de la propiedad intelectual en la Red plantea un cambio sustancial en cuanto a la aplicación de los ordenamientos jurídicos nacionales como instrumento básico en defensa de los intereses en juego.

La universalización de las redes de telecomunicaciones y el acceso desde cualquier parte del mundo a los contenidos integrados en internet, obligan a recurrir a los convenios y tratados internacionales reguladores, con el fin de aplicar una normativa acorde con esta nueva, y previsiblemente expansiva, realidad.

Conviene, a estos efectos, tener presente que los ya clásicos acuerdos de Berna y Ginebra ${ }^{1}$ están siendo complementados con otros tratados entre los que cabe destacar el realizado por la Ompi $^{2}$ (Organización Mundial de la Propiedad Intelectual) y el surgido de la Ronda de Uruguay ${ }^{3}$. Además, existe un creciente impulso de armonización internacional en el que la UE colabora con un especial protagonismo y que tiene su reflejo en los libros verdes ${ }^{4}$ sobre la materia, en las directivas sobre temas relacionados con la propiedad intelectual y en la propuesta de directiva sobre derechos de autor ${ }^{5}$.

http://www.wipo.org/

Asimismo, hay que tener presente que junto a la regulación jurídica de la defensa de la propiedad intelectual se está avanzando en el establecimiento de procesos e instrumentos de protección técnica y en las mejoras, con idénticos tratamientos, de la gestión de los derechos de autor mediante métodos de marcado más o menos invisibles y de elusión o bloqueo de copias de documentos electrónicos.

\section{«Empieza a haber cada día más boletines que Ilegan hasta los buzones en formato web y que pueden interpretarse por un programa de correo si está con- figurado para ello»}

Conscientes de esta nueva realidad, en los desarrollos normativos nacionales e internacionales que inciden en la regulación de los derechos de autor van apareciendo cada vez en mayor medida especificaciones tendentes a la reglamentación de estos procesos técnicos, aportando cobertura legal a los mismos e imponiendo sanciones a quienes ilícitamente traten de elu-

\title{
Próximos números monográficos
}

\author{
Mayo $2000 \quad$ Hemeroteca virtual \\ Septiembre 2000 Consultores en recursos de información \\ Diciembre $2000 \quad$ Información en ciencias de la salud
}

Los interesados pueden remitir notas, artículos, propuestas, publicidad, comentarios, etc., sobre estos temas a:

epi@sarenet.es 
dir, desactivar o modificar los instrumentos de protección tecnológica adheridos a los documentos susceptibles de protección jurídica.

\section{A favor y en contra de la edición electrónica}

Para terminar, habría que resaltar algunas consideraciones finales. La presencia en internet de las revistas científicas a texto completo es una demanda de la sociedad de la información. Esto supone un reto que tiene que afrontar la industria editorial tradicional (edición en papel) y además en el corto espacio de tiempo en el que se ha desarrollado la edición electrónica.

Todo período de cambio conlleva una incertidumbre donde subsisten muchos factores, unos a favor y otros en contra. Entre los favorables se encuentran el abaratamiento de los costes, su gran versatilidad en obtención de diversos formatos, rapidez en la publicación de los artículos, accesibilidad total, difusión en todo el mundo, etc. Entre los inciertos se encuentran la forma de financiación, derechos de autor, revisión de los artículos, etc.

Lo que sí es un hecho constatado es que las revistas impresas tienen cada vez menos suscripciones y para compensar tienen que aumentar su precio, mientras que el número en la Red a texto completo es cada día mayor. Así pues, el futuro en este campo es indeterminado pero parece razonable esperar, como ha ocurrido ya con la aparición de otros medios de información (televisión y radio), que no tiene que desaparecer ninguna de las opciones y que cada una de ellas tendrá un público asegurado.

Nota: Agradecemos al Dr. J. Páez, especialista del Cindoc en propiedad intelectual, su asesoramiento.

\section{Notas}

1. Convenio de Berna para la protección de obras literarias y artísticas, revisado en París el 24 de julio de 1971. Convención universal sobre los derechos de autor, revisada en París el 24 de julio de 1971.

2. Tratado de la Ompi sobre derechos de autor, adoptado en Ginebra por la Conferencia Diplomática el 20 de diciembre de 1996.

3. Anexo 1C. Acuerdos sobre los aspectos de los derechos de propiedad intelectual relacionados con el comercio, del acuerdo por el que se establece la Organización Mundial del Comercio y Acuerdos anexos, formalizados en Marrakech, el 15 de abril de 1994.

4. Libro verde sobre los derechos de autor y los derechos afines en la sociedad de la información.

5. Propuesta de directiva del Parlamento Europeo y del Consejo relativa a la armonización de determinados aspectos de los derechos de autor y derechos afines en la sociedad de la información.

\section{Bibliografía}

Caridad Sebastián, Mercedes (coord.). La sociedad de la información. Política, tecnología e industria de los contenidos. Madrid: Centro de Estudios Ramón Areces, 1999.
Casino, Gonzalo. "España, más tecnología que contenido". En: El país, 1999, 27 de enero.

http://www.acta.es/xml/intro_xml-html.htm

http://jamillan.com

Eíto Brun, Ricardo. "Common ground: ¿una alternativa de Acrobat?”. En: El profesional de la información, 1998, enero-febrero, v. 7, n. 1-2, pp. 12-17.

Gallart, Núria. "Propiedad intelectual en la era electrónica". En: El profesional de la información, 1999, junio, v. 8, n. 6, pp. 36-38.

García Caballero, Ricardo; Martín Galán, Bonifacio. "Herramientas para la gestión de los documentos electrónicos en los nuevos servicios de información y documentación". En: $7^{a s}$ Jornadas catalanas de documentación. Expodoc' 99, 1999.

García Testal, Cristina; Barrueco Cruz, José Manuel. "Algunos apuntes sobre edición científica electrónica y derechos de autor". En: El profesional de la información, 1998, abril, v. 7, n. 4, pp. 7-11.

Hípola, Pedro. “Edición electrónica: ¿con qué formato?”. En: Information world en español, 1995, febrero, n. 31, pp. 1-8.

Hípola, Pedro. "El mercado de la información electrónica". En: I Jornadas andaluzas de documentación, 1997, pp. 21-25.

Hípola, Pedro; Moya, Félix. "Proyectos EDI y normalización documental". En: Revista española de documentación científica, 1991, v. 14, n. 4, pp. 408-419.

Hitchcock, Steve; Carr, Leslie; Hall, Wendy. "Web journals publishing: a UK perspective". En: Serials, 1997, noviembre, v. 10, n. 3, pp. 285-299. http://jamillan.com/locomotora.htm

Lafuente López, Ramiro; Rosas Gutiérrez, Angélica María. "La publicación electrónica: ¿un paradigma de organización documental digital?”. En: Investigación bibliotecológica: archivonomía, bibliotecología e información, 1998, julio-diciembre, v. 25, n. 12, pp. 164-196.

Lois, Concha; Jaudenes, María. "Edición electrónica y servicios bibliográficos”. En: Revista general de información y documentación, 1997, v. 7, n. 1, pp. 153-167.

Martín Carbajal, Francisco. "La edición electrónica y las redes de telecomunicación”. En: Urogallo, 1995, mayo-junio, n. 108-109, pp. 32-37.

Millán, José Antonio. "La edición electrónica y sus metamorfosis". Consultado en: 04-01-2000.

http://jamillan.com

Montero, Ramón. "Xml, el lenguaje universal". Consultado en: 12-011999.

http://www.acta.es/xml/intro_xml-html.htm

Pajares Tosca, Susana. "Espacio digital y publicaciones electrónicas”. En: Jornadas sobre publicación electrónica, 1999.

Razquin Zazppe, Pedro. "Del hipertexto al multimedia interactivo. Evolución, situación actual, y perspectivas de los sistemas y aplicaciones multimedia”. En: Revista general de información y documentación, 1997, v. 7, n. 1, pp. 107-132.

Redero Hernández, Ángel Luis. "Buscadores de revistas electrónicas". En: El profesional de la información, 1998, abril, v. 7, n. 4, pp. 3-6.

Rodríguez Gómez, Joaquín. "La locomotora digital. Lo que las revistas pueden hacer por el futuro de la edición”. Consultado en: 19-01-2000. http://jamillan.com/locomotora.htm

Villalón Panzano, Javier; Aguillo Caño, Isidro. "Revistas electrónicas en ciencias sociales y humanidades". En: Revista española de documentación científica, 1998, julio-septiembre, v. 21, n. 3, pp. 303-316.

Elena Fernández Sánchez e Isabel Fernández Morales. Centro de información y documentación científica, Cindoc, Csic. Madrid.

elenaf@cindoc.csic.es

ifemo@cindoc.csic.es 